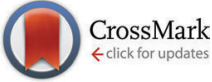

Cite this: Phys. Chem. Chem. Phys., 2016, 18, 2080

Received 25th October 2015 Accepted 14th December 2015

DOI: $10.1039 / c 5 c p 06477 e$

www.rsc.org/pccp

\section{Protonated thiophene-based oligomers as formed within zeolites: understanding their electron delocalization and aromaticity $\dagger$}

\begin{abstract}
Diego Valencia, Gareth T. Whiting, Rosa E. Bulo and Bert M. Weckhuysen*
In an earlier work, protonated thiophene-based oligomers were identified inside ZSM-5 zeolites. The novel compounds exhibited $\pi-\pi^{*}$ absorption wavelengths deep within the visible region, earmarking them for possible use as chromophores in a variety of applications. In this computational study, we determine the factors that cause such low-energy transitions, and describe the electronic structure of these remarkable compounds. DFT calculations of conjugated thiophene-based oligomers with up to five monomer units reveal that the main absorption band of each protonated oligomer is strongly red-shifted compared to the unprotonated form. This effect is counterintuitive, since protonation is expected to diminish aromaticity, and thereby increase the HOMO-LUMO gap. We find that upon protonation the $\pi$-electrons remain delocalized over the entire $\pi$-conjugated molecule, but the positive charge is localized predominantly on the protonated side of the molecule. A possible explanation for this ground-state charge localization is the participation of the $\mathrm{C}-\mathrm{H}$ bond in the $\pi$-system of the protonated ring, locally providing aromatic stabilization for the positive charge. The addition of the proton stabilizes all electronic orbitals, but due to the ground state $\pi$-electron distribution away from the added nucleus, the HOMO is stabilized less than the LUMO. The main absorption peak upon protonation corresponds to the charge transfer excitation involving the frontier orbitals, and the small band gap explains the observed red shift. Analogue calculations on thiophene within a ZSM-5 zeolite cluster model confirm the same trends upon protonation as observed in the non-interacting compounds. Understanding the electronic structure of these compounds is very relevant to correlate UV-Vis bands with acidic strength and possibly environment in zeolites and to improve their performance in catalytic and energy related applications.
\end{abstract}

\section{Introduction}

Thiophene-based oligomers have been characterized and applied to the development of conductive polymers ${ }^{1}$ as well as organic solar cells. ${ }^{2}$ They have remarkable optic, electronic, charge transfer and redox properties as well as prominent supramolecular behaviour on solid surfaces or at the bulk. ${ }^{3}$ Several thiophenebased compounds have been successfully synthesized and characterized, where the long chain oligomers are the more promising systems to date. They have conductive properties and lightabsorbing regions that can be enlarged to cover low-energy/ long-wavelength spectra (visible region). ${ }^{4,5}$

Recently, we reported the structures of protonated thiophenebased oligomers formed within zeolites by protonation and

Inorganic Chemistry and Catalysis group, Debye Institute for Nanomaterials Science, Utrecht University, Universiteitsweg 99, 3584 CG Utrecht, The Netherlands.

E-mail: b.m.weckhuysen@uu.nl

$\dagger$ Electronic supplementary information (ESI) available: TD-DFT benchmark calculations, optimized geometries, HOMO and LUMO plots, NICS values for PAHs, theoretical IR spectra, protonation energies and coordinates. See DOI: 10.1039/c5cp06477e oligomerization processes. ${ }^{6}$ Formation of those compounds can be followed by micro-spectroscopic techniques, as developed in our group for selective staining studies of zeolite-based materials to discriminate between regions of high- and low acidity (Scheme 1). ${ }^{7-10}$ The selective formation of different types of these compounds is related to the Brønsted acid site strength, determined by the chemical and structural composition of the zeolite. ${ }^{11}$ Although the formation of S-containing byproducts with zeolites had been reported previously, their chemical structure had remained unclear. $^{12-14}$ DFT calculations have now made understanding their structure and determination viable. However, some questions still need to be answered.

Five-membered heterocyclic compounds, such as thiophene ( $6 \pi$ electrons), are aromatic according to Hückel's rule. Once a proton is added to the thiophene-based oligomers, an electron pair is removed from the $\pi$ ring system (Scheme 1A). A remarkable characteristic of these protonated oligomers is the presence of UV-Vis absorption bands deep in the visible region (Scheme 1B). ${ }^{6-14}$ This result is unexpected, since protonation of an aromatic compound should diminish aromaticity, which generally results 
(A)

in an increase of the HOMO-LUMO gap. This feature makes them viable candidates for application as chromophores in a variety of fields; characterization of catalyst bodies, solar cells, and conductive polymers. ${ }^{1-11}$

To a lesser degree, red shifts in UV-Vis absorption of polyaromatic hydrocarbons (PAH) upon protonation have been recently observed for compounds formed in the interstellar medium as well as in zeolites. ${ }^{15-18}$ The red shift in PAH derivatives ${ }^{19}$ has been related to the strong charge transfer character of the electronic transition. While the protonation of thiophene oligomers has not been computationally investigated, a related work addressed the effect of electron withdrawing substituents in the $\alpha$-position on UV-Vis absorption. ${ }^{20}$ The observed red shift was related to the different stabilization effects of the substituents on the HOMO and the LUMO. A thorough study of ionized tri- and tetracation thiophene oligomers, after removal of several electrons from the $\pi$-system, found chargecarrying areas of approximately five monomers long, on which each positive charge was localized. ${ }^{21}$

The oligomerization of thiophene can produce several different compounds from two distinct pathways: oligomerization and/or ring-opening reactions. Formation of these compounds and their stability within zeolites depends on several factors such as reaction temperature, $\mathrm{Si} / \mathrm{Al}$ ratio, pore size, etc. (Scheme 1). In this work, we present a detailed description of the electronic structure of the unprotonated and protonated thiophene-based oligomers consisting of one to five monomers ( $n \mathrm{~T}$ and $n \mathrm{~T}-\mathrm{H}^{+}$, where $n=$ number of thiophene oligomer units), and use this to explain the extraordinary optical properties of these compounds. Finally, we discuss the thiophene protonation mechanism, and the role of the zeolite in the process.

\section{Computational details}

The ground state structures of non- and protonated thiophenebased oligomers were obtained by means of Density Functional Theory (DFT) calculations. The optimized geometry for each compound was obtained using the hybrid meta GGA density functional M06- $2 \mathrm{X}^{22}$ with the $6-31+\mathrm{G}(\mathrm{d}, \mathrm{p})$ standard basis set. All harmonic vibrational frequencies were real; therefore the structures are minima on the potential energy surface.

Time dependent (TD)-DFT excited states calculations of singletsinglet transitions were carried out with different functionals: B3LYP ${ }^{23,24}$ M06, ${ }^{22}$ M06-2X ${ }^{22}$ and CAM-B3LYP ${ }^{25}$ for benchmark calculations. The effect of the basis set was also evaluated with $6-31+G(d, p)$ and $6-311++G(d, p)$ for benchmark calculations. The range-separated CAM-B3LYP functional, known for its proper description of asymptotic effects, shows similar performance to the M06-2X functional. This indicates that the latter functional is able to accurately capture the charge transfer excitations ${ }^{26,27}$ (Fig. S1, ESI $\dagger$ ) and it was chosen for the calculation of the excitation energies for all the compounds. The ground state geometries were employed throughout all excited state calculations. Thus, the theoretical excitation energies correspond to vertical transitions, which can be approximately identified as band maxima in experimental absorption spectra.

Nucleus-Independent Chemical Shifts (NICS) values were calculated for the optimized geometries at M06-2X/6-31+G(d,p) level of theory using the continuous set of the gauge transformation method. Because the NICS values are distant dependent, the ghost atoms $(\mathrm{Bq})$ were placed on the geometrical centre of each heterocyclic ring $(z=0)$. Hirshfeld charge analysis ${ }^{28}$ was performed at the same level of theory.

A reaction mechanism of thiophene protonation was obtained using a cluster model of ZSM-5 zeolite containing 22 tetrahedral atoms ( 99 atoms total). The model was built from the coordinates of MFI zeolite framework and terminated with $\mathrm{H}$ atoms. The Brønsted acid site was produced by substitution of $\mathrm{Si}$ with $\mathrm{Al}$ atom and introducing a proton in the adjacent $\mathrm{O}$ atom. Geometry optimizations with this cluster were carried out at M06-2X/6$31+\mathrm{G}(\mathrm{d}, \mathrm{p})$ level. The reaction mechanism was confirmed by using M06-2X/6-311++G(2d,2p) level, where the same reaction profile and energies were obtained. The interacting surface atoms of the ZSM-5 zeolite ( $\mathrm{Si}, \mathrm{Al}, \mathrm{O}$ or $\mathrm{H})$ (4 atoms) and the adsorbed nonand protonated thiophene were allowed to relax during the calculation while bulk atoms were fixed. All harmonic vibrational frequencies were real for the non- and protonated thiophene adsorbed on ZSM-5; therefore the structures are minima on the potential energy surface. The transition state (TS) structure has only one imaginary frequency. An intrinsic reaction coordinate calculation was performed to confirm that the TS connects thiophene and protonated thiophene properly.

All the calculations were performed with the Gaussian 09 software. ${ }^{29}$ 


\section{Results and discussion}

\subsection{Electronic properties}

The thiophene-based oligomers show a change in their absorption band $(\lambda)$ as the number of monomer units increases (Table 1 ). Thiophene (T) shows the band of the $\pi-\pi^{*}$ transition at $206 \mathrm{~nm}$, whereas one of the largest thiophene-based oligomer in this study, 5T, is located at $411 \mathrm{~nm}$. It is important to note that their bands are mostly in the UV region. The protonated thiophenebased oligomers have their $\pi-\pi^{*}$ transition at higher wavelength than the non-protonated counterparts (Table 2). The absorption bands for the protonated thiophene-based oligomers with 3,4 and 5 thiophenic units are in the visible region: 455, 555 and $651 \mathrm{~nm}$, respectively. We found a remarkable agreement between the calculated values and the experimental reported ones, which is a consequence of the proper selection of the theoretical approach for both neutral and protonated compounds. The difference between HOMO and LUMO energy $\left(\Delta \varepsilon_{\mathrm{H}-\mathrm{L}}\right)$ has the same trend as the absorption bands. This band gap is narrowed for the larger thiophene-based oligomers $(3 \mathrm{~T}=5.45 \mathrm{eV}, 4 \mathrm{~T}=5.00 \mathrm{eV}$ and $5 \mathrm{~T}=4.73 \mathrm{eV})$. The trend of the absorption band position with increasing number of oligomer unit is in good agreement with previous results. ${ }^{30,31}$ Protonated thiophene-based oligomers have a much lower band gap than their non-protonated counterparts $\left(3 \mathrm{~T}-\mathrm{H}^{+}=4.99 \mathrm{eV}, 4 \mathrm{~T}-\mathrm{H}^{+}=3.45 \mathrm{eV}\right.$ and $\left.5 \mathrm{~T}-\mathrm{H}^{+}=2.91 \mathrm{eV}\right)$. The differences in the $\Delta \varepsilon_{\mathrm{H}-\mathrm{L}}$ for the protonated thiophene-based oligomers are in good agreement with the red-shift in absorption band of the $\pi-\pi^{*}$ transition. The comparison of both non- and protonated thiophene-based oligomers is in good agreement with the red-shift on aromatic compounds upon protonation. ${ }^{15}$

Table 1 Absorption band of the $\pi-\pi^{\star}$ transition $(\lambda)$, oscillator strength ( $f$ ), frontier orbitals energies, HOMO-LUMO gap $\left(\Delta \varepsilon_{\mathrm{H}-\mathrm{L}}\right)$ and dipole moments $(\mu)$ for thiophene-based oligomers $(n T$, where $n=$ number of thiophene conjugated rings). Level of theory $M 06-2 X / 6-31+G(d, p)$

\begin{tabular}{|c|c|c|c|c|c|c|}
\hline Compound & $\lambda^{a}(\mathrm{~nm})$ & $f$ & $\varepsilon_{\text {номо }}(\mathrm{eV})$ & $\varepsilon_{\text {LUMO }}(\mathrm{eV})$ & $\Delta \varepsilon_{\mathrm{H}-\mathrm{L}}(\mathrm{eV})$ & $\mu(\mathrm{D})$ \\
\hline $\mathrm{T}$ & $206(224)$ & 0.105 & -8.00 & 0.37 & 8.37 & 0.53 \\
\hline $2 \mathrm{~T}$ & 293 (303) & 0.398 & -7.01 & -0.70 & 6.31 & 0.00 \\
\hline $3 \mathrm{~T}$ & $348(357)$ & 0.735 & -6.61 & -1.16 & 5.45 & 0.52 \\
\hline $4 \mathrm{~T}$ & 385 (391) & 1.107 & -6.41 & -1.41 & 5.00 & 0.00 \\
\hline $5 \mathrm{~T}$ & 411 (n.r.) & 1.488 & -6.29 & -1.56 & 4.73 & 0.52 \\
\hline
\end{tabular}

${ }^{a}$ Experimental values reported in ref. 14 are shown in parentheses, n.r. $=$ not reported in literature.

Table 2 Absorption band of the $\pi-\pi^{*}$ transition $(\lambda)$, oscillator strength $(f)$, frontier orbitals energies, HOMO-LUMO gap $\left(\Delta \varepsilon_{\mathrm{H}-\mathrm{L}}\right)$ and dipole moments $(\mu)$ for protonated thiophene-based oligomers $\left(n T-\mathrm{H}^{+}\right.$, where $n=$ number of thiophene conjugated rings). Level of theory M06-2X/6-31+G(d,p)

\begin{tabular}{llllllr}
\hline Compound & $\lambda^{a}(\mathrm{~nm})$ & $f$ & $\varepsilon_{\text {HOMO }}(\mathrm{eV})$ & $\varepsilon_{\text {LUMO }}(\mathrm{eV})$ & $\Delta \varepsilon_{\mathrm{H}-\mathrm{L}}(\mathrm{eV})$ & $\mu(\mathrm{D})$ \\
\hline $\mathrm{T}-\mathrm{H}^{+}$ & $276(263)$ & 0.125 & -14.59 & -7.64 & 6.95 & 1.32 \\
$2 \mathrm{~T}-\mathrm{H}^{+}$ & $347(333)$ & 0.504 & -12.29 & -6.83 & 5.46 & 2.31 \\
$3 \mathrm{~T}-\mathrm{H}^{+}$ & $455(417)$ & 0.964 & -10.60 & -6.41 & 4.99 & 5.05 \\
$4 \mathrm{~T}-\mathrm{H}^{+}$ & $555(550)$ & 1.343 & -9.60 & -6.15 & 3.45 & 8.66 \\
$5 \mathrm{~T}-\mathrm{H}^{+}$ & $651(650)$ & 1.582 & -8.91 & -6.00 & 2.91 & 13.67
\end{tabular}

${ }^{a}$ Experimental values reported in ref. 6 and 14 are shown in parentheses.

\subsection{Molecular orbitals}

HOMO and LUMO plots for the largest molecules (5T and $5 \mathrm{~T}-\mathrm{H}^{+}$) are displayed in Fig. 1. They show a symmetric electron density distribution along the non-protonated compound. A different distribution is observed for its protonated form. This molecule has a larger proportion of HOMO electron density located at the atoms in the opposite part of the molecule to where the proton was added. In contrast, the LUMO density is located mostly on the atoms near the added proton. The frontier orbital plots for the smaller oligomers exhibited the same behaviour upon protonation (Fig. S3, ESI $\dagger$ ). The plots of the frontier orbitals show that charge transfer excitation is taking place in the protonated thiophene-based oligomers. The addition of an extra nucleus reduces the energy of all electronic orbitals (Tables 1 and 2), but the stabilizing influence affects the HOMO less than the LUMO. This can be explained by the fact that the HOMO electron density is further away from the added core charge than the LUMO. The unfavourable electron-nucleus interaction in the HOMO explains the decreased HOMO-LUMO gap after protonation and thereby the red shift of the main absorption band. In the subsections below, we will address the reasons behind the observed HOMO charge distribution.

The shape of frontier MO density distribution in the protonated thiophene-based oligomers resembles that of so-called push-pull molecules, ${ }^{32-34}$ where electron-donor and electron-acceptor substituents are used to polarize the $\pi$-electron system of organic materials and then producing red-shifts due to a proper combination of the substituents. In this case, the proton introduced by zeolites polarizes the electron cloud of the aromatic thiophenebased oligomers. Dipole moment $(\mu)$ values of the thiophene-based oligomers are shown in Table 1. Molecules with odd number of monomer units show $\mu$ around $0.52 \mathrm{D}$ and the even ones have a $\mu=0 \mathrm{D}$. On the other hand, the protonated thiophene-based oligomers show very high dipole moments values (from 1.32 to $13.67 \mathrm{D})$ that increase as the monomer units increase (Table 2).

\subsection{Structural parameters}

The optimized geometries for both non- and protonated thiophene-based oligomers are planar along the entire molecule. The hybridization of the protonated $\mathrm{C}_{\alpha}$ atom changed from $\mathrm{sp}^{2}$ to $\mathrm{sp}^{3}$ after the process. Optimized geometries and selected bond lengths are shown in Fig. S2 (ESI $\dagger$ ). The respective bond lengths in each individual ring in the non-protonated thiophene-based oligomers are almost identical. The $\mathrm{C}-\mathrm{C}$ bond length between two different thiophenic units is around $1.45 \AA$. The addition of the proton on one thiophene ring changes the bond distances in

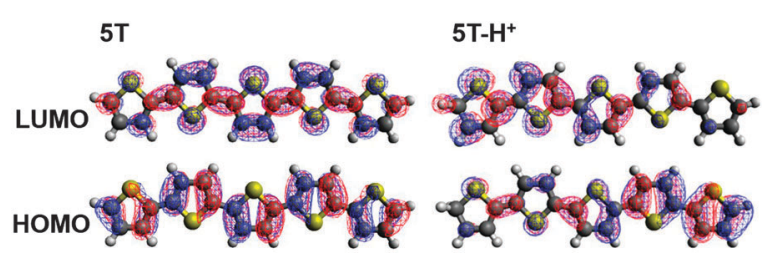

Fig. 1 Highest occupied molecular orbital (HOMO) and lowest unoccupied molecular orbital (LUMO) plots of $5 \mathrm{~T}$ and $5 \mathrm{~T}-\mathrm{H}^{+}$compounds. 
the entire molecule. As expected, the protonated ring undergoes a more drastic change than the neighbours. The $\mathrm{C}-\mathrm{C}$ bond length between the protonated ring and its adjacent neighbour is smaller than the respective one for the non-protonated counterpart $\left(1.41 \AA\right.$ for $2 \mathrm{~T}-\mathrm{H}^{+}, 1.39 \AA$ for $3 \mathrm{~T}-\mathrm{H}^{+}$and $4 \mathrm{~T}-\mathrm{H}^{+}$, and $1.38 \AA$ for $5 \mathrm{~T}-\mathrm{H}^{+}$). The $\mathrm{C}-\mathrm{C}$ bond lengths of adjacent neighbouring rings are also affected.

We display a comparison between the non- and protonated thiophene-based oligomers in Fig. 2 to illustrate the effect of the protonation on the bond distances. The $\mathrm{C}-\mathrm{C}$ bond lengths of the protonated ring is strongly affected. $\mathrm{T}$ and $\mathrm{T}-\mathrm{H}^{+}$seem to alternate the single and double $\mathrm{C}-\mathrm{C}$ bonds as typically have been drawn. The effect of the protonation on the $\mathrm{C}-\mathrm{C}$ bond lengths for the larger oligomers showed that the neighbouring thiophenic rings are also affected. For instance, $5 \mathrm{~T}$ compound shows three different values of its $\mathrm{C}-\mathrm{C}$ bond lengths, which correspond to single and double bonds and the link between each oligomer. 5T- $\mathrm{H}^{+}$exhibits similar behaviour from 16 to 19 $\mathrm{C}-\mathrm{C}$ bonds. Modification and alternation from $\mathrm{C}-\mathrm{C}$ bonds 1-15 due to the proton addition suggest the electronic distribution in the entire molecule is not simply $\mathrm{C}-\mathrm{C}$ single or double bonds. It is clear that the rings adjacent to the protonated one change drastically their $\mathrm{C}-\mathrm{C}$ bond lengths and the opposite part of the molecule is almost not affected. This modification in the bond lengths caused by the protonation suggests that each ring is still conjugated along the complete compound.

\subsection{Charge localization}

Distribution of the positive charge in the thiophene-based oligomers was also analysed (Fig. 3). As expected, the nonprotonated compounds have zero charge in the entire system
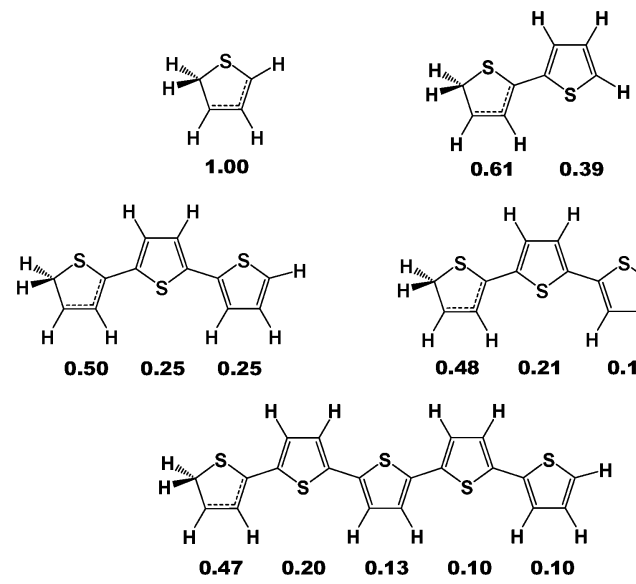

Fig. 3 Charge analysis in protonated thiophene-based oligomers. The positive charge to each ring is displayed below.

and at each individual monomer. Surprisingly, the positive charge distribution on the protonated thiophene-based oligomers is not localized only on the protonated thiophene ring. Charge analysis reveals that the positive charge is mostly contained in the protonated thiophene ring. However, the vicinal thiophene rings hold part of the charge, which is in good agreement with the $\mathrm{C}-\mathrm{C}$ bond lengths, orbital shapes, and dipole moments. The complete molecule suffered drastic changes in the $\mathrm{C}-\mathrm{C}$ bond lengths and the orbital shapes showed the localization of HOMO mainly on the opposite part of the molecule where the proton was added. A charge separation takes place in the molecule, which is more pronounced for the bigger protonated thiophene-based oligomers. Previous calculations of tri- and
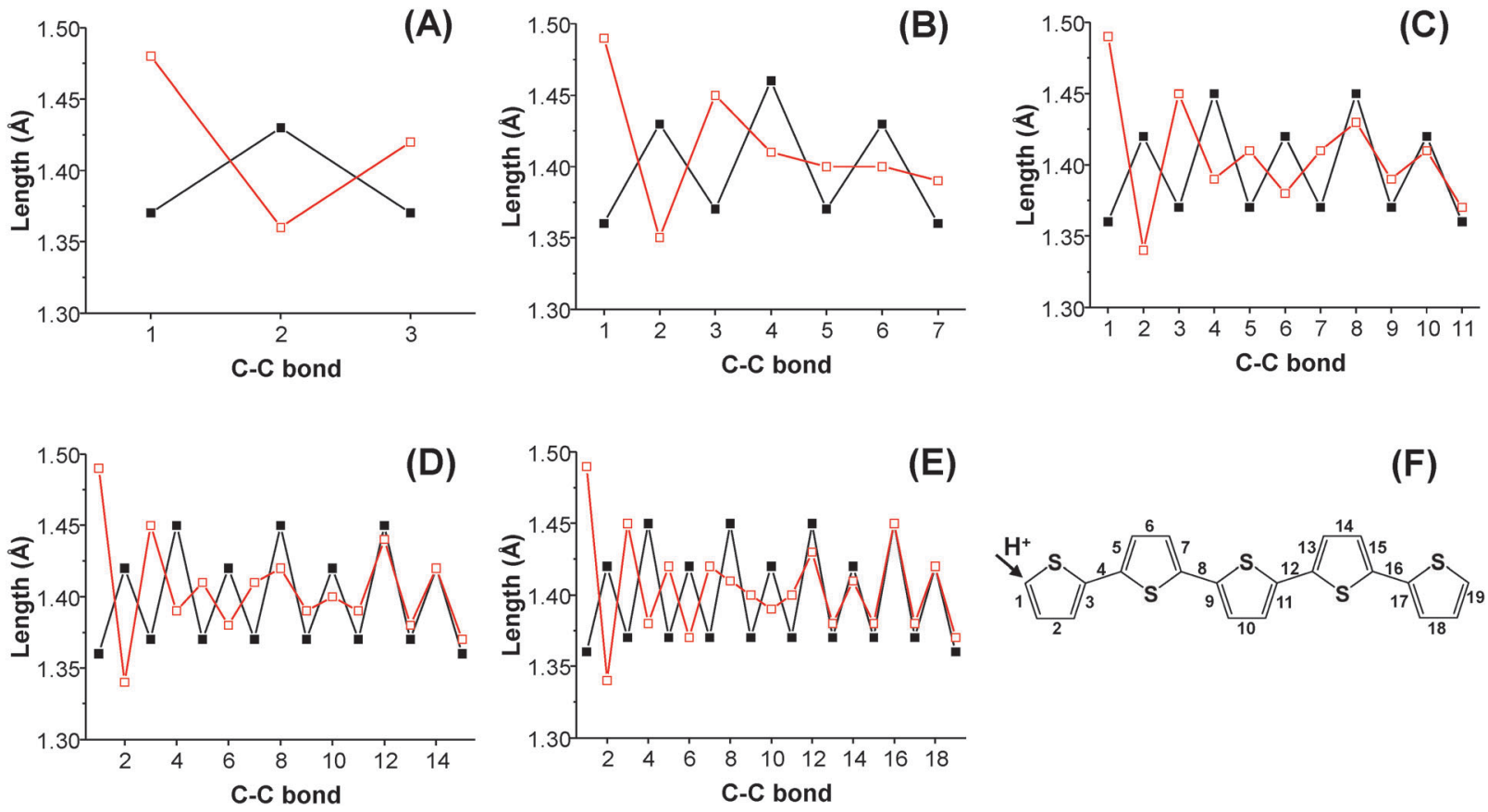

(F)

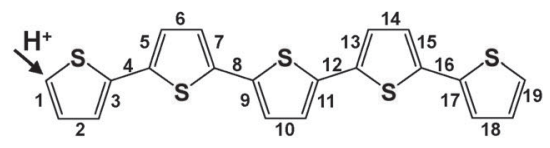

Fig. $2 \mathrm{C}-\mathrm{C}$ bond lengths and their variation before (filled square) and after (empty square) protonation of $\mathrm{C}_{\alpha}$ atom for: (A) T, (B) 2T, (C) 3T, (D) 4T, (E) 5T oligomers and (F) $\mathrm{C}-\mathrm{C}$ bonds in $5 \mathrm{~T}$ oligomer as reference, the protonated $\mathrm{C}_{\alpha}$ atom is shown by an arrow. 
tetracation thiophene-based oligomers showed charge-carrying areas, each capable of bearing one polaron, in separated regions of the chain. ${ }^{33}$ Our smaller systems show that the positive charge stays mainly in the protonated ring of the protonated thiophenebased oligomers and it produces molecules with higher charge separation within the planar systems. For instance, $3 \mathrm{~T}-\mathrm{H}^{+}$has 0.50 in the protonated ring, 0.25 in the near neighbour and 0.25 in the third thiophenic unit; the case of $5-\mathrm{H}^{+}$is also distributed with $0.47,0.20,0.13,0.10$ and 0.10 .

Based on the electronic properties described above, we can draw a schematic picture of the charge distribution that takes place in the thiophene-based oligomers as depicted in Scheme 2. For all oligomers, the dominant resonance structure mainly places the charge on the protonated ring, resulting in the charge gradient. The participation of sulphur atom is also taken into account on the resonant aromatic structures. It is important to note that the electrons are delocalized along the entire system. The observed localization of the positive charge on the protonated ring reflects the localization of the HOMO electron density on the opposite side of the molecule (Section 3.2).

\subsection{NICS}

Nucleus-independent chemical shifts (NICS), ${ }^{35}$ as an aromaticity criterion, were calculated for both thiophene-based oligomers with the values presented in Fig. 4. The NICS values for nonprotonated thiophene-based compounds are higher compared to the protonated counterparts (e.g. thiophene: -14.4 and protonated thiophene: -6.9 ). In other words, the addition of the proton on the aromatic systems is reducing the magnetic current. The negative NICS values indicate that the proton reduces the aromatic stabilization energy of the thiophene-based compounds, but they are still aromatic compounds. Increasing the number of monomers in the thiophene oligomers produces differences in the NICS values. The inner ring systems showed lower values $(-10.7)$ than those at outer regions $(-12.4)$, which is in agreement with the HOMO electron distribution and with

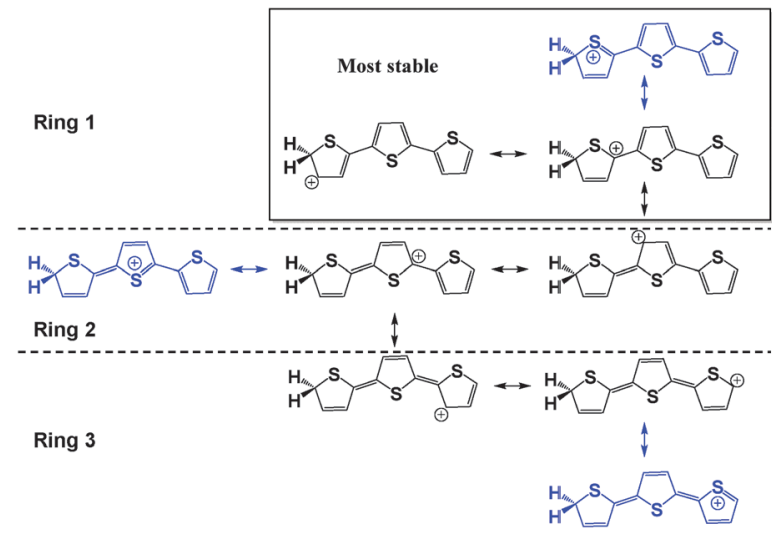

Scheme 2 Resonant structures for the protonated thiophene-based oligomers. $3 \mathrm{~T}-\mathrm{H}^{+}$was used to illustrate the charge transfer. Molecules drawn with black described the charge located on carbon atoms, whereas the possible localization on sulphur atom is displayed in the blue structures. Atomic charges combined with bond lengths data suggest that the top resonance structure dominates.

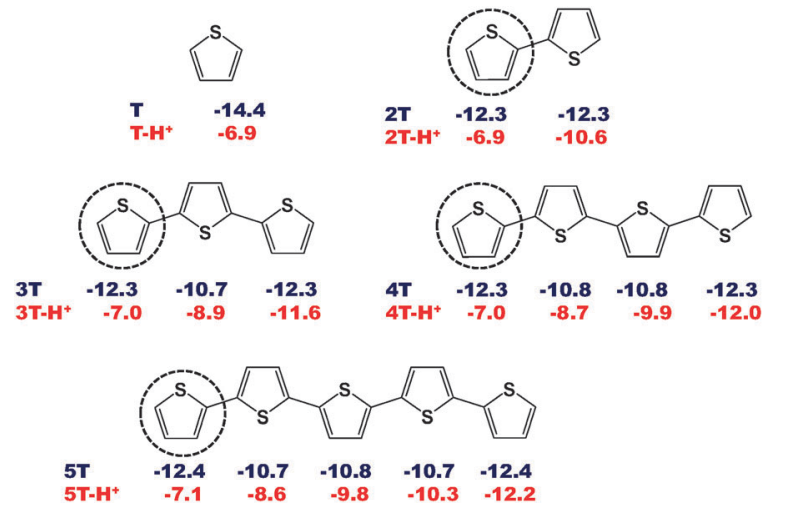

Fig. 4 Nucleus-independent chemical shifts (NICS) values for non- and protonated thiophene-based oligomers. NICS values for non-protonated compounds are in blue and the corresponding for protonated ones are in red. The protonated ring is highlighted by a dotted circle.

previous NICS studies. ${ }^{36}$ This scenario changes when the proton is added to the aromatic thiophene oligomers (Fig. 4). The NICS value for the protonated ring is the least negative (less aromatic) in the molecule. It is important to note that NICS values of the neighbouring rings have also been affected by the addition of the proton. These values are in good agreement with the $\mathrm{C}-\mathrm{C}$ bond lengths, HOMO plots and dipole moments, where the NICS values indicate that the opposite side of the molecule is less affected by the proton addition. A possible explanation for the retained aromaticity in the protonated ring could be the involvement of the $\mathrm{C}-\mathrm{H}$ bond electrons in the $\alpha$-protonated thiophenebased oligomers the $\pi$ electrons in the molecule. In this manner, the positively charged ring retains electrons in the $\pi$-system and aromaticity is maintained after protonation. ${ }^{37}$ We studied representative linear polycyclic aromatic hydrocarbons (PAHs) as they have been reported elsewhere. ${ }^{19}$ The protonation of these molecules results in a red-shift on the $\pi-\pi^{*}$ transition due to charge transfer. The NICS values for the PAHs compounds (Fig. S4, ESI $\dagger$ ) showed that the protonation process produces an antiaromatic benzene ring, which is unstable thermodynamically. The dipole moments for the neutral and protonated PAHs compounds are also reported in Table S1 (ESI $\dagger$ ). The higher the dipole moment, the higher the red-shift is. The dipole moment values for the selected PAHs are smaller compared to the ones obtained for the thiophene-based oligomers. With this comparison we point out the stronger charge transfer within the thiophenebased compounds upon protonation. It is well-known that thiophene shows versatile and unique electron properties that have made it attractive for light absorption applications. ${ }^{1-5}$ Furthermore, the protonated thiophene-based oligomers belong to this outstanding family.

We found participation of the neighbouring thiophenic rings in compensating the electronic structure due to the addition of a proton to the aromatic compounds by zeolites. Electrons are still delocalized within the protonated molecules. Most likely, the aromatic character of the protonated thiophenebased oligomers is only retained if the positive charge is localized on the protonated ring. Retaining aromaticity thus explains the 
ground state charge distribution, and thereby the relatively high energy of the HOMO (Section 3.2). Therefore, the lower HOMOLUMO gap observed in the protonated compounds with respect to the neutral oligomers, and the observed red-shift are combined effects of electron delocalization, charge separation and aromaticity.

\subsection{Protonation of oligomers}

The electronic properties of the thiophene-based compounds described above, explain the red-shift of the wavelength of these compounds upon protonation. Moreover, we calculated thermodynamic stability and their formation within the ZSM-5 zeolite. Protonation of thiophene-based oligomers by gas phase $\mathrm{H}_{3} \mathrm{O}^{+}$is an exergonic process that is more favourable as the number of thiophenic units increases (Table S2, ESI $\dagger$ ): $\mathrm{T}=-108 \mathrm{~kJ} \mathrm{~mol}^{-1}, 3 \mathrm{~T}=-220 \mathrm{~kJ} \mathrm{~mol}^{-1}$ and $5 \mathrm{~T}=-246 \mathrm{~kJ} \mathrm{~mol}^{-1}$. Furthermore, the protonation of these thiophene-based oligomers by an acidic oxygen is thermodynamically possible. In order to gain more insights into their production within zeolites, this process was further studied. The reaction mechanism of the thiophene protonation by a Brønsted acid site of ZSM-5 zeolite is shown in Fig. 5. It is clear that the protonation process is thermodynamically and kinetically favourable, with an overall protonation energy of $-74 \mathrm{~kJ} \mathrm{~mol}^{-1}$. We pointed out the possibility of protonation of thiophene by the Brønsted acid sites present in the zeolites. The transition state structure of the thiophene is interesting because it is possible to appreciate the proton transfer reaction from the $\mathrm{O}$ atom in the Brønsted acid site to the $\mathrm{C}_{\alpha}$ in the thiophene. Thiophene is also changing its $\mathrm{C}_{\alpha}$ hybridization from $\mathrm{sp}^{2}$ to $\mathrm{sp}^{3}$. The protonated molecule is still adsorbed and interacting with the Brønsted acid site. Protonated thiophene can further react with another thiophene molecule to form oligomers, this mechanism has been proposed elsewhere. ${ }^{38}$

We performed TD-DFT calculations for the non- and protonated thiophene interacting with ZSM-5 zeolite cluster shown in Fig. 5. The absorption wavelength of the thiophene is $216 \mathrm{~nm}$ compared to the non-interacting compound, where a red-shift of $10 \mathrm{~nm}$ was observed. The protonated thiophene adsorbed on ZSM-5 cavity shows an absorption band of the $\pi-\pi^{*}$ transition

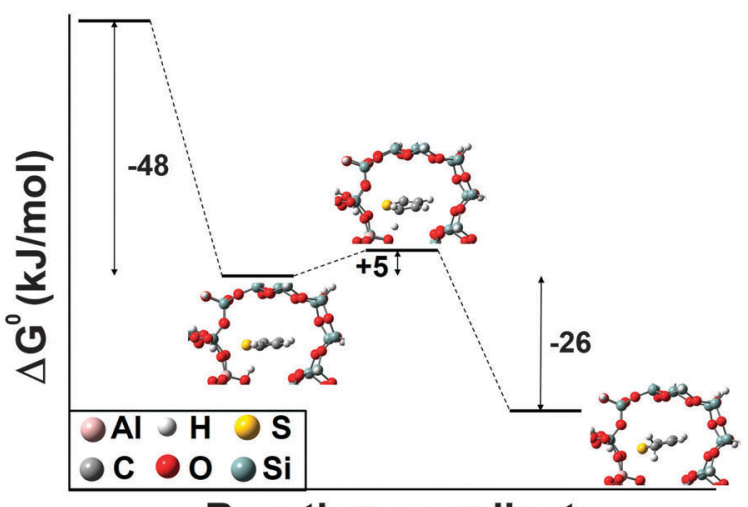

Reaction coordinate

Fig. 5 Mechanism of thiophene protonation catalysed by a Brønsted acid site of zeolite ZSM-5. at $290 \mathrm{~nm}$ that is red-shifted $14 \mathrm{~nm}$ compared to its free version. These results showed the effect of the zeolite environment on the protonation process. The absorption band positions are very close to the non-interacting compounds, with slight differences imposed by the ZSM-5 zeolite, but this is essential to their formation and stabilization.

The NICS values were also computed for the thiophene and protonated thiophene on ZSM-5 zeolite, to have a better overview of the effect of the ZSM-5 confinement on their electronic structure. The NICS values of the thiophene adsorbed on ZSM-5 is -13.0 and -5.4 for the protonated thiophene. Compared to the non-interacting molecules those values are smaller, but the effect of the protonation process is the same. The NICS values of both S-containing molecules interacting with ZSM-5 zeolite are in good agreement with the $\pi-\pi^{*}$ transition band position shifts. This decrement in the NICS values is a consequence of the confinement effect due to the cavities in the ZSM-5 zeolite and the interaction through the Brønsted acid site. The study of the larger oligomers in zeolites is still a computing challenge and their calculated properties such as NICS values, as we can appreciate for the smaller oligomers, did not vary significantly by the addition of the proton.

Properties of protonated thiophene-based compounds formed within zeolites are attractive from the chemical standpoint. The protonated thiophene-based oligomers showed a red-shift in the $\pi-\pi^{*}$ transition, which is surprising from the aromatic point of view. Herein, we showed the interesting electronic properties, where aromaticity, polarization, electron and charge transfer take place in the entire aromatic system. The larger the oligomer size is, the larger the electron distribution effect is.

\section{Conclusions}

We have explored the electronic structure of protonated thiophenebased oligomers, which are remarkable chemical compounds that can provide insights into the role of electron delocalization, polarization, charge transfer and aromaticity. We note the cooperative participation of all the monomer units in the thiophenebased oligomers to stabilize and distribute the electron density upon protonation. A red-shift in the main absorption band due to the addition of the proton is a consequence of the charge localization motivated by aromatic stabilization in these molecules. The main absorption bands of the larger protonated thiophene-based oligomers are located mostly in the visible region. Zeolites can easily produce those protonated compounds due to the presence of the Brønsted acid sites. Selective formation of these compounds within zeolites is a complex process that could be tuned by different reaction conditions. A proper combination of the Brønsted acid site strength in zeolites with thiophene could be attractive for future applications.

\section{Acknowledgements}

Dutch national e-infrastructure with the support of the SURF Foundation is acknowledged for providing time in Lisa cluster 
computer. B. M. W. acknowledges financial support from the Netherlands Organisation for Scientific Research (NWO) Gravitation Program (Netherlands Center for Multiscale Catalytic Energy Conversion, MCEC) and a TOP NOW-CW Grant, as well as ERC Advanced Grant (321140).

\section{Notes and references}

1 S. Kirchmeyer and K. Reuter, J. Mater. Chem., 2005, 15, 2077-2088.

2 J. Xue, B. P. Rand, S. Uchida and S. R. Forrest, Adv. Mater., 2005, 17, 66-71.

3 C. Lin, T. Endo, M. Takase, M. Iyoda and T. Nishinaga, J. Am. Chem. Soc., 2011, 133, 11339-11350.

4 F. Zhang, D. Wu, Y. Xua and X. Feng, J. Mater. Chem., 2011, 21, 17590-17600.

5 K. Schulze, C. Uhrich, R. Schüppel, K. Leo, M. Pfeiffer, E. Brier, E. Reinold and P. Bäuerle, Adv. Mater., 2006, 18, 2872-2875.

6 G. T. Whiting, F. Meirer, D. Valencia, M. M. Mertens, A.-J. Bons, B. M. Weiss, P. A. Stevens, E. Smit and B. M. Weckhuysen, Phys. Chem. Chem. Phys., 2014, 16, 21531-21542.

7 B. M. Weckhuysen, Angew. Chem., Int. Ed., 2009, 48, 4910-4943.

8 M. H. F. Kox, A. Mijovilovich, J. J. H. B. Sattler, E. Stavitski and B. M. Weckhuysen, ChemCatChem, 2010, 2, 564-571.

9 J. Ruiz-Martínez, I. L. C. Buurmans, W. V. Knowles, D. van der Beek, J. A. Bergwerff, E. T. C. Vogt and B. M. Weckhuysen, Appl. Catal., A, 2012, 419-420, 84-94.

10 I. L. C. Buurmans, J. Ruiz-Martínez, W. V. Knowles, D. van der Beek, J. A. Bergwerff, E. T. C. Vogt and B. M. Weckhuysen, Nat. Chem., 2011, 3, 862-867.

11 J. V. Caspar, V. Ramamurthy and D. R. Corbin, J. Am. Chem. Soc., 1991, 113, 600-610.

12 C. L. García and J. A. Lercher, J. Phys. Chem., 1992, 96, 2669-2675.

13 H. H. Shan, C. Y. Li, C. H. Yang, H. Zhao, B. Y. Zhao and J. F. Zhang, Catal. Today, 2002, 77, 117-126.

14 (a) F. Geobaldo, G. Turnes Palomino, S. Bordiga, A. Zecchina and C. Otero Areán, Phys. Chem. Chem. Phys., 1999, 1, 561-569; (b) D. Birnbaum, D. Fichou and B. E. Kohler, J. Chem. Phys., 1992, 96, 165-169.

15 B. S. Freiser and J. L. Beauchamp, J. Am. Chem. Soc., 1977, 99, 3214-3225.

16 M. Hammonds, A. Pathak and P. J. Sarre, Phys. Chem. Chem. Phys., 2009, 11, 4458-4464.

17 L. Palumbo, F. Bonino, P. Beato, M. Bjørgen, A. Zecchina and S. Bordiga, J. Phys. Chem. C, 2008, 112, 9710-9716.

18 K. Hemelsoet, Q. Qian, T. De Meyer, K. De Wispelaere, B. De Sterck, B. M. Weckhuysen, M. Waroquier and V. Van Speybroeck, Chem. - Eur. J., 2013, 19, 16595-16606.

19 I. Alata, C. Dedonder, M. Broquier, E. Marceca and C. Jouvet, J. Am. Chem. Soc., 2010, 132, 17483-17489.

20 G. Daminelli, J. Widany, A. Di Carlo and P. Lugli, J. Chem. Phys., 2007, 115, 4919-4923.
21 S. S. Zade and M. Bendikov, J. Phys. Chem. C, 2007, 111, 10662-10672.

22 Y. Zhao and D. G. Truhlar, Theor. Chem. Acc., 2007, 120, 215-241.

23 A. D. Becke, J. Chem. Phys., 1993, 98, 1372-1377.

24 C. Lee, W. Yang and R. G. Parr, Phys. Rev. B: Condens. Matter Mater. Phys., 1998, 37, 785-789.

25 T. Yanai, D. Tew and N. Handy, Chem. Phys. Lett., 2004, 393, 51-57.

26 A. Charaf-Eddin, A. Planchat, B. Mennucci, C. Adamo and D. Jacquemin, J. Chem. Theory Comput., 2013, 9, 2749-2760.

27 D. Jacquemin, Y. Zhao, R. Valero, C. Adamo, I. Ciofini and D. G. Truhlar, J. Chem. Theory Comput., 2012, 8, 1255-1259. 28 F. L. Hirshfeld, Theor. Chim. Acta, 1977, 44, 129-138.

29 M. J. Frisch, G. W. Trucks, H. B. Schlegel, G. E. Scuseria, M. A. Robb, J. R. Cheeseman, G. Scalmani, V. Barone, B. Mennucci, G. A. Petersson, H. Nakatsuji, M. Caricato, X. Li, H. P. Hratchian, A. F. Izmaylov, J. Bloino, G. Zheng, J. L. Sonnenberg, M. Hada, M. Ehara, K. Toyota, R. Fukuda, J. Hasegawa, M. Ishida, T. Nakajima, Y. Honda, O. Kitao, H. Nakai, T. Vreven, J. A. Montgomery, Jr., J. E. Peralta, F. Ogliaro, M. Bearpark, J. J. Heyd, E. Brothers, K. N. Kudin, V. N. Staroverov, R. Kobayashi, J. Normand, K. Raghavachari, A. Rendell, J. C. Burant, S. S. Iyengar, J. Tomasi, M. Cossi, N. Rega, J. M. Millam, M. Klene, J. E. Knox, J. B. Cross, V. Bakken, C. Adamo, J. Jaramillo, R. Gomperts, R. E. Stratmann, O. Yazyev, A. J. Austin, R. Cammi, C. Pomelli, J. W. Ochterski, R. L. Martin, K. Morokuma, V. G. Zakrzewski, G. A. Voth, P. Salvador, J. J. Dannenberg, S. Dapprich, A. D. Daniels, Ö. Farkas, J. B. Foresman, J. V. Ortiz, J. Cioslowski and D. J. Fox, Gaussian 09, Revision B.01, Gaussian, Inc., Wallingford CT, 2009.

30 (a) H. Sun and J. Autschbach, J. Chem. Theory Comput., 2014, 10, 1035-1047; (b) F. Liu, P. Zuo, L. Meng and S. J. Zheng, J. Mol. Struct.: THEOCHEM, 2005, 726, 161-169.

31 Y. Kanemitsu, K. Suzuki and Y. Masumoto, Phys. Rev. B: Condens. Matter Mater. Phys., 1994, 50, 2301-2305.

32 T. Vijayakumar, I. Hubert Joe, C. P. Reghunadhan Nair and V. S. Jayakumar, Chem. Phys., 2008, 343, 83-99.

33 C. Ravikumar, I. Hubert Joe and V. S. Jayakumar, Chem. Phys. Lett., 2008, 460, 552-558.

34 M. Maldonado-Domínguez, R. Arcos-Ramos, M. Romero, B. Flores-Pérez, N. Farfán, R. Santillan, P. G. Lacroix and I. Malfant, New J. Chem., 2014, 38, 260-268.

35 P. von Ragué Schleyer, C. Maerker, A. Dransfeld, H. Jiao and N. J. R. van Eikema Hommes, J. Am. Chem. Soc., 1996, 118, 6317-6318.

36 D. Delaere, M. T. Nguyen and L. G. Vanquickenborne, Phys. Chem. Chem. Phys., 2002, 4, 1522-1530.

37 J. D. Mosley, A. M. Ricks, P. v. R. Schleyer, J. I. Wu and M. A. Duncan, J. Phys. Chem. A, 2012, 116, 9689-9695.

38 B. Li, W. Guo, S. Yuan, J. Hu, J. Wang and H. Jiao, J. Catal., 2008, 253, 212-220. 